\title{
Efeito da densidade populacional de Panicum maximum (cultivar Tanzânia) na fitorremediação de solo contaminado com o herbicida picloram
}

\section{Effect of the populational densities of Panicum maximum (cultivar Tanzânia) in phytoremediation of polluted soil with picloram herbicide}

\author{
Sergio de Oliveira Procópio; ${ }^{1}$ Marcos Lima do Carmo²; Fábio Ribeiro Pires ${ }^{3 *}$; \\ Alberto Cargnelutti Filho ${ }^{4}$; Guilherme Braga Pereira Braz ${ }^{5}$; Welington Fernando \\ Peres Silva ${ }^{5}$; Alberto Leão de Lemos Barroso ${ }^{6}$; Gilson Pereira Silva ${ }^{6}$; Eduardo \\ Lima do $\mathrm{Carmo}^{2}$; Antonio Joaquim Braga Pereira Braz ${ }^{6}$, Leandro Pereira Pacheco ${ }^{7}$
}

\section{Resumo}

O objetivo desse trabalho foi avaliar a influência da densidade populacional de Panicum maximum (cultivar Tanzânia) sobre a fitorremediação de solo contaminado com o herbicida picloram. O experimento foi conduzido em casa-de-vegetação, de setembro de 2006 a fevereiro de 2007. Os tratamentos foram compostos pela combinação entre quatro densidades populacionais da espécie vegetal Panicum maximum (cultivar Tanzânia) (0, 5, 10 e 15 plantas por vaso, equivalentes a 0, 122, 244 e 366 plantas $\mathrm{m}^{2}$, respectivamente) e de três doses do picloram $\left(0,80\right.$ e $160 \mathrm{~g} \mathrm{ha}^{-1}$ aplicadas diretamente nos vasos, simulando níveis de contaminação do solo). Após o cultivo da espécie fitorremediadora por 100 dias, efetuou-se, no próprio vaso, a semeadura da espécie bioindicadora da presença do picloram, soja (cultivar Monsoy 6101), na qual foram avaliadas a fitotoxicidade, a altura de plantas e a massa verde e seca da parte aérea. A densidade populacional da espécie fitorremediadora Tanzânia influenciou o nível de fitotoxicidade do herbicida picloram sobre a cultura da soja semeada em sucessão. Das densidades populacionais avaliadas, 122 plantas $\mathrm{m}^{-2}$ foi a mais eficiente na descontaminação do solo.

Palavras-chave: Residual de herbicidas, descontaminação do solo, Glycine max

\footnotetext{
Abstract

This research was carried out from September of 2006 to February of 2007, under greenhouse conditions, in Rio Verde - GO/ Brazil to study the influence of Panicum maximum populational density

1 Pesquisador da Embrapa Tabuleiros Costeiros, Av. Beira Mar, 3.250, Praia 13 de Julho, CEP: 49.025-040, Aracaju-SE, E-mail: procópio@cpatc.embrapa.br, Telefone: (79) 4009-1318, Bolsista do CNPq.

2 Mestrando do Programa de Pós-Graduação da Fesurv - Universidade de Rio Verde, Faz. Fontes do Saber s/n, Rio Verde, GO, CEP 75.901-970.

3 Professor Adjunto do DCSBA, Centro Universitário Norte do ES/UFES. R. Rodovia RB 101 Norte, Km 60, Bairro Litorâneo, São Mateus, ES. CEP: 29932-540. fabiopires@pq.cnpq.br; Telefone: (27) 3763-8689, Bolsista do CNPq.

4 Professor Adjunto do Departamento de Fitotecnia da Universidade Federal de Santa Maria. Avenida Roraima s/n, Campus Camobi - Santa Maria, RS. CEP: 97105-900. cargnelutti@pq.cnpq.br

5 Graduando em Agronomia, Universidade de Rio Verde. Faz. Fontes do Saber s/n, Rio Verde, GO, CEP 75.901-970.

6 Professor Adjunto da Faculdade de Agronomia, Universidade de Rio Verde, GO, CEP 75.901-970. gilson@,fesurv.br

7 Doutorando em Agronomia, UFG. Rod. Goiânia Nova Veneza Km zero, Campus II, Goiânia, GO, CEP: 74.001-970. leandroppacheco@gmail.com (Fone: 648128 4269; Bolsista CAPES).

* Autor para correspondência
} 
on the phytoremediation of soil contaminated with picloram. The treatments were the combination of four Panicum maximum (cultivar Tanzânia) populational densities $(0,5,10$ e 15 plants per pot, corresponding to a $0,122,244$ and 366 plants $\mathrm{m}^{-2}$, respectively) and three rates of picloram $(0,80$ and $160 \mathrm{~g} \mathrm{ha}^{-1}$ applied directly on the pots, simulating levels of soil contamination). After cultivating the phytoremediator specie on substrate during 100 days, soybean Glycine max L was sown at the same pot, used as a phytotoxicity bioindicator specie. Height of plants and green and dry mass of the above ground part of soybean were evaluated. The population density of the phytoremediate species Tanzania influenced the level of phytotoxicity of the herbicide picloram soybean crop sowed in succession. The population density of , 122 plants $\mathrm{m}^{-2}$ was the most efficient in the decontamination of the soil.

Key words: Carryover. Soil decontamination. Glycine max.

\section{Introdução}

A sustentabilidade passou a ser umas das palavras mais importantes para designar a modificação do enfoque dos sistemas agrícolas brasileiros. "Manejo Integrado de Pragas, Doenças e Plantas Daninhas", "Manejo Ecológico de Pragas, Doenças e Plantas Daninhas", "Agricultura Orgânica", "Agricultura Alternativa", "Produção Integrada de Frutas", "Aproveitamento de Resíduos Orgânicos", "Racionalização no Uso de Insumos Agrícolas", são expressões cada vez mais presentes nos projetos de pesquisa e nas diretrizes dos programas de extensão rural das instituições responsáveis pelo desenvolvimento, agora "sustentável" do agronegócio do País.

A fitorremediação é uma técnica que está sendo desenvolvida para atenuar a poluição dos agrotóxicos e viabilizar o plantio de variedades mais sensíveis como a soja (PIRES et al., 2003). A utilização de plantas com capacidade de descontaminar poluentes presentes em solos ou recursos hídricos (PILONSMITS, 2005), vem sendo consolidada no momento em que nunca se empregou tamanha quantidade de defensivos agrícolas nas lavouras do País. Dentre os poluentes que apresentam maior potencial contaminante ao ambiente destacam-se os herbicidas de longa atividade residual nos solos, podendo-se citar os princípios ativos picloram, tebuthiuron, sulfentazone, imazapyr, imazaquinetrifloxysulfuronsodium, entre os mais problemáticos. Efeitos negativos como a toxicidade a organismos não-alvo (ROUSSEAUX et al., 2003); a lixiviação aos lençóis freáticos (KOLPIN; THURMAN; GOOLSBY,
1996; LERCH; BLANCHARD; THRUMAN, 1998; LERCH et al., 1995; THURMAN et al., 1992); o carreamento junto às partículas de argila ou de matéria orgânica, resultando na deposição em cursos hídricos superficiais (BARRA et al., 1999; KRUTZ et al., 2005; PALMA et al., 2004); e a intoxicação em culturas sensíveis semeadas em seqüência na mesma área (carryover) (BRIGHENTI et al., 2002; JAKELAITIS et al., 2006; VILLA et al., 2006), são exemplos que podem ocorrer após a utilização desses insumos químicos. No Brasil, programas de fitorremediação dos herbicidas trifloxysulfuronsodium e tebuthiuron já se encontram em níveis mais avançados (PIRES et al., 2005a, 2005b; 2006; PROCÓPIO et al., 2005a, 2005b, 2007; SANTOS et al., 2004).

A transformação de pastagens em áreas agrícolas tem se tornado prática comum, principalmente na região do Cerrado Brasileiro. No entanto, caso o herbicida picloram tenha sido utilizado na pastagem, visando ao controle de plantas invasoras, normalmente arbustivas ou arbóreas, a área fica impossibilitada de ser cultivada com culturas sensíveis a esse herbicida, como a soja, o tomate, o feijão, o algodão e as cucurbitáceas em geral, por pelo menos três anos. Além da questão da utilização da terra para fins agrícolas, outro ponto preocupante é que esse herbicida ainda apresenta alta solubilidade em água, o que favorece sua movimentação vertical no perfil dos solos, podendo atingir e se distribuir nas águas subterrâneas (SANTOS et al., 2006b).

É importante salientar que a fitorremediação tem como objetivo central reduzir a biodisponibilidade 
e com isso a fitotoxicidade, permitindo o plantio de uma cultura sensível ao picloram como a soja; também pode, com isso, impedir ou diminuir a contaminação dos recursos hídricos. No entanto, outros benefícios podem advir da implementação dessa técnica. Como exemplos tem-se o aumento do teor de matéria orgânica do solo; a reciclagem de nutrientes; a fixação biológica do nitrogênio (dependendo da espécie utilizada); a proteção do solo contra processos erosivos; a redução de problemas com patógenos de solo, como os fitonematóides; e o aumento da biodiversidade (PIRES et al., 2003). Todos esses fatores levam à conclusão de que a fitorremediação possui vários atributos que podem auxiliar no desenvolvimento de sistemas agrícolas sustentáveis.

O objetivo desse trabalho foi avaliar a influência da densidade populacional de Panicum maximum (cultivar Tanzânia) sobre a fitorremediação de solo contaminado com o herbicida picloram.

\section{Material e métodos}

O experimento foi conduzido em casa-devegetação da Fesurv - Universidade de Rio Verde, localizada no município de Rio Verde-GO, cujas coordenadas geográficas são: latitude de 1747'24" S e longitude de $50^{\circ} 56^{\prime} 31^{\prime}$ W, e altitude de 698 metros. O período de condução do experimento foi de setembro de 2006 a fevereiro de 2007.

Os tratamentos foram compostospela combinação entre quatro densidades populacionais da espécie vegetal Panicum maximum (cultivar Tanzânia) (0, 5, 10 e 15 plantas por vaso com área média de 0,0408 $\mathrm{m}^{2}$ e capacidade para $8 \mathrm{dm}^{3}$, equivalente a 0,122 , 244 e 366 plantas $\mathrm{m}^{2}$, respectivamente) e de três doses do picloram $\left(0,80 \mathrm{e} 160 \mathrm{~g} \mathrm{ha}^{-1}\right)$, totalizando 12 tratamentos. $\mathrm{O}$ delineamento experimental utilizado foi o inteiramente casualizado em esquema fatorial $4 \times 3$, com quatro repetições.

Como substrato para o crescimento das plantas, utilizaram-se amostras de solo classificado como Latossolo Vermelho eutroférrico, cuja análise química e física se encontra na Tabela 1. Antes do preenchimento dos vasos, o solo foi corrigido com calcário filler, utilizando-se o equivalente a $2 \mathrm{t} \mathrm{ha}^{-1}$, e adubado com o equivalente a $500 \mathrm{~kg} \mathrm{ha}^{-1}$ da fórmula 08-20-18.

Tabela 1. Composição físico-química do solo utilizado no experimento. Rio Verde-GO. 2006/2007

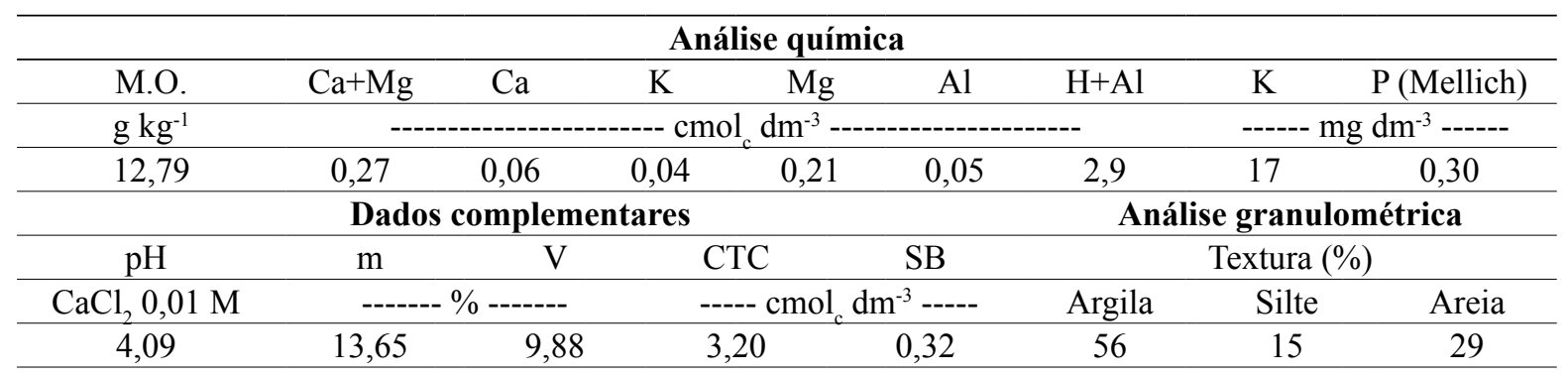

*Análises realizadas nos Laboratórios de Análises Físicas e Químicas de Solo da Faculdade de Agronomia da Fesurv - Universidade de Rio Verde, segundo a metodologia descrita pela Empresa Brasileira de Pesquisa AgropecuáriaEMBRAPA (1997). 
Após o preenchimento e umedecimento dos vasos, procedeu-se à aplicação do herbicida picloram, utilizando-se um pulverizador costal pressurizado com $\mathrm{CO}_{2}$, acoplado de barra contendo duas pontas de pulverização TT 110.02, aplicando volume de calda equivalente a $200 \mathrm{~L} \mathrm{ha}^{-1}$. Após 48 horas da aplicação do herbicida foi realizada a semeadura da espécie vegetal fitorremediadora. Dez dias após a emergência das plantas realizouse um desbaste, deixando-se o número de plantas por vaso correspondente a cada tratamento. Todos os vasos foram irrigados duas vezes ao dia, para a manutenção da umidade do solo.

Ao término do tempo estabelecido para atuação da espécie vegetal (100 dias após a emergência), ela foi dessecada com glyphosate (1.800 $\mathrm{g} \mathrm{ha}^{-1} \mathrm{de}$ equivalente ácido), e cinco dias após, as plantas foram cortadas na altura do coleto, sendo a parte aérea descartada. A seguir, foram retiradas amostras de solo de todos os vasos, sendo estas analisadas quimicamente ( $\mathrm{pH}$, macro e micronutrientes - dados não apresentados). Após a análise dos resultados procedeu-se uma adubação de plantio específica para cada tratamento, a fim de se uniformizar a disponibilidade de nutrientes em cada unidade experimental. Terminada esta etapa efetuou-se a semeadura da espécie bioindicadora da presença do picloram, soja (Glycine max cultivar Monsoy 6101), distribuindo-se 10 sementes por vaso. Após a emergência das plantas da espécie bioindicadora, procedeu-se um desbaste deixando-se três plantas por vaso. Novamente, como na etapa anterior, todos os vasos foram irrigados duas vezes ao dia.

Aos 15 e 40 dias após a emergência (DAE) das plantas bioindicadoras avaliou-se a fitotoxicidade de forma visual - utilizando-se escala percentual, onde 0 (zero) significa ausência de sintomas, e $100 \%$ morte de todas as plantas, e a altura de plantas, utilizando-se escala graduada, tendo como referência o meristema apical. Aos $40 \mathrm{DAE}$ as plantas bioindicadoras foram cortadas rente ao solo, sendo o material vegetal imediatamente pesado em balança analítica, determinando-se a massa verde da parte aérea, e colocado em estufa de circulação forçada de ar $\left(70 \pm 2{ }^{\circ} \mathrm{C}\right)$ por 72 horas, e pesados novamente em balança analítica, determinando-se assim a massa seca da parte aérea.

Após a coleta e tabulação dos dados, estes foram submetidos à análise de variância. A análise dos efeitos significativos da densidade populacional da espécie fitorremediadora dentro de cada dose do herbicida foi realizada por análise de regressão, sendo os coeficientes das equações testados pelo teste $\mathrm{t}$ a 5\% de significância, cujos equações foram ajustadas conforme a variável em questão e seu respectivo comportamento biológico. Os efeitos significativos das doses do picloram, em cada densidade populacional, foram verificados por meio do teste de Tukey a 5\% de significância, devido ao número insuficiente de níveis para o ajuste das equações de regressão.

\section{Resultados e discussão}

Houve interação significativa entre as doses de picloram e as densidades de Tanzânia, sendo, portanto, apresentado o desdobramento dessa interação. O cultivo prévio das plantas de Tanzânia reduziu substancialmente a fitotoxicidade sobre as plantas de soja, decorrente dos resíduos do herbicida picloram presente no solo (Tabela 2 e Figura 1). Todavia, a densidade populacional das plantas de Tanzânia influenciou na eficácia da técnica remediadora. Quando não se efetuou o cultivo prévio das plantas de Tanzânia, as injúrias verificadas nas plantas de soja, aos 15 dias após a emergência (DAE), ultrapassaram 92\% nos dois níveis de contaminação do herbicida $\left(80\right.$ e $\left.160 \mathrm{~g} \mathrm{ha}^{-1}\right)$. Esses resultados mostram que a soja é uma espécie extremamente sensível a presença do picloram no solo, o que reforça o cuidado com o plantio dessa leguminosa em áreas onde esse herbicida tenha sido empregado anteriormente. Segundo Wax, Knuth e Slife (1969), a cultura da soja apresenta sensibilidade a quantidades extremamente baixas do herbicida picloram no solo. 
Tabela 2. Fitotoxicidade em plantas de soja semeadas após o cultivo prévio de Panicum maximum (cultivar Tanzânia), em quatro densidades populacionais, em solo contaminado com três níveis do herbicida picloram. Rio Verde, GO. 2006/2007.

\begin{tabular}{|c|c|c|c|c|}
\hline \multirow{3}{*}{ Doses de picloram $\left(\mathrm{g} \mathrm{ha}^{-1}\right)$} & \multicolumn{4}{|c|}{ Plantas de Panicum maximum (cultivar Tanzânia) $\mathrm{m}^{-2}$} \\
\hline & 0 & 122 & 244 & 366 \\
\hline & \multicolumn{4}{|c|}{ Fitotoxicidade (\%) em plantas de soja aos 15 DAE* $^{*}$} \\
\hline 0 & $0,00 \mathrm{~b}$ & $0,00 \mathrm{a}$ & $0,00 \mathrm{~b}$ & $0,00 \mathrm{~b}$ \\
\hline 80 & $92,75 \mathrm{a}$ & $3,75 \mathrm{a}$ & $13,00 \mathrm{ab}$ & $15,75 \mathrm{~b}$ \\
\hline \multirow[t]{2}{*}{160} & $95,75 \mathrm{a}$ & $9,25 \mathrm{a}$ & $14,33 \mathrm{a}$ & $50,00 \mathrm{a}$ \\
\hline & \multicolumn{4}{|c|}{ Fitotoxicidade (\%) em plantas de soja aos 40 DAE } \\
\hline 0 & $0,00 \mathrm{~b}$ & $0,00 \mathrm{~b}$ & $0,00 \mathrm{~b}$ & $0,00 \mathrm{c}$ \\
\hline 80 & $97,75 \mathrm{a}$ & $19,50 \mathrm{ab}$ & $35,00 \mathrm{a}$ & $40,25 \mathrm{~b}$ \\
\hline 160 & $96,00 \mathrm{a}$ & $21,25 \mathrm{a}$ & $31,25 \mathrm{a}$ & $66,00 \mathrm{a}$ \\
\hline
\end{tabular}

Médias não seguidas de mesma letra na vertical diferem pelo teste de Tukey a $5 \%$ de probabilidade. $*$ DAE $=$ dias após a emergência. **a e b representam as comparações entre médias pelo de Tukey a $5 \%$.

$15 \mathrm{DAE}$

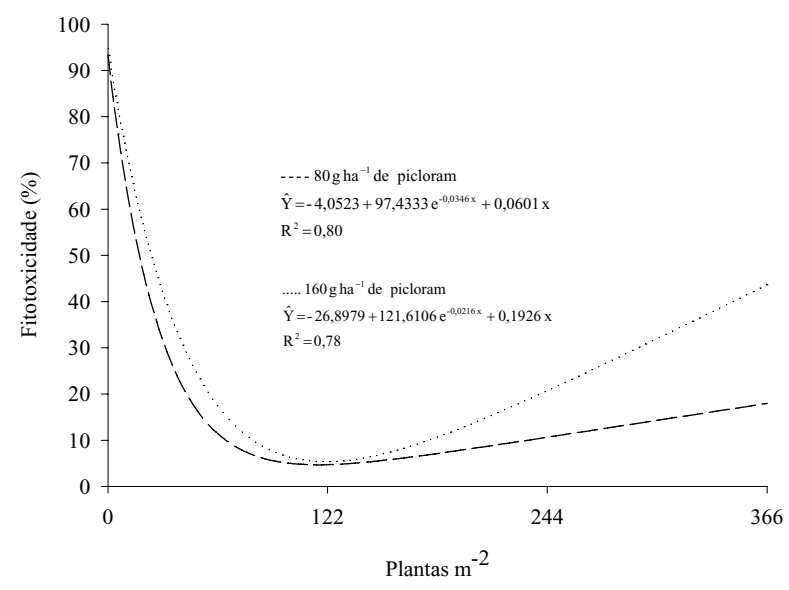

40 DAE

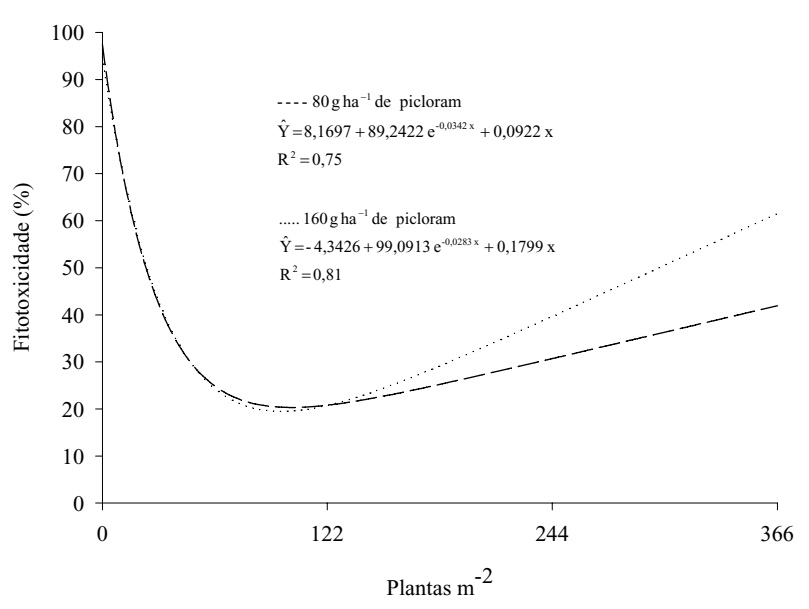

Figura 1. Fitotoxicidade em plantas de soja, aos 15 e 40 dias após a emergência (DAE), semeadas após o cultivo prévio de Panicum maximum (cultivar Tanzânia), em função da densidade populacional, em solo contaminado com dois níveis do herbicida picloram. Rio Verde, GO. 2006/2007.

O cultivo prévio de todas as densidades populacionais avaliadas de Tanzânia (122, 244 e 366 plantas $\mathrm{m}^{-2}$ ) resultou em diminuição significativa da intoxicação das plantas de soja aos 15 DAE (abaixo de 16\%), quando o nível de contaminação inicial era de $80 \mathrm{~g} \mathrm{ha}^{-1}$ de picloram, porém maior descontaminação ocorreu com a utilização de 122 plantas $\mathrm{m}^{-2}(3,75 \%$ de fitotoxicidade) (Tabela 2 e Figura 1. Esse fato também foi observado quando se aplicou previamente $160 \mathrm{~g} \mathrm{ha}^{-1}$ do herbicida, pois o cultivo prévio de 122 plantas $\mathrm{m}^{-2}$ de Tanzânia acarretou em 9,25\% de intoxicação às plantas de soja, em comparação à 50,00\%, quando se empregou 366 plantas $\mathrm{m}^{-2}$ (Tabela 2). Com a análise dos dados ficou evidente que a partir da densidade de 122 plantas $\mathrm{m}^{-2}$ de Tanzânia começa a ocorrer prejuízos no processo de fitorremediação de solos contaminados com picloram, sendo esse efeito mais acentuado no maior nível de contaminação do solo (Figura 1). A densidade adequada dependerá primordialmente da espécie utilizada, porém, de acordo com Schnoor e Dee (1997), que trabalharam com espécies arbóreas 
como agentes fitorremediadores, alta densidade populacional no início de seu estabelecimento assegura taxa significativa de evapotranspiração, o que normalmente é desejável, até certo ponto, a partir do qual a competição intraespecífica pode prejudicar o desenvolvimento das plantas.

Aos 40 DAE, mesmo comportamento foi verificado na avaliação de fitotoxicidade das plantas de soja, ou seja, queda na eficiência remediadora das plantas de Tanzânia se cultivada em densidade superior a 122 plantas $\mathrm{m}^{-2}$ (Figura 1), contudo os níveis de fitotoxicidade observados em todos os tratamentos foram mais acentuados. Apesar desse cenário, a utilização de 122 plantas $\mathrm{m}^{-2}$ de Tanzânia continuou garantindo bons resultados, proporcionando níveis de intoxicação às plantas de soja inferiores a $22 \%$ aos $40 \mathrm{DAE}$, mesmo quando essa planta bioindicadora foi cultivada em solo que recebeu anteriormente $160 \mathrm{~g} \mathrm{ha}^{-1}$ de picloram (Tabela 2). Nesse maior nível de contaminação, foi constatado uma intoxicação média das plantas de soja de $96,00 \%$ quando não houve a fitorremediação, ou seja, praticamente a morte de todas as plantas dessa leguminosa. Segundo Santos et al. (2006a), aumentos da densidade populacional de plantas remediadoras em determinada área, até certo limite, também podem proporcionar maior volume de raízes e de solo explorado, podendo resultar em incremento da absorção/degradação do contaminante e/ou degradação rizosférica. Portanto, era de se esperar que com o aumento da densidade, houvesse redução da fitotoxicidade, decorrente do incremento na fitorremediação promovida pelo Tanzânia, todavia, no presente trabalho, esse efeito não foi observado. A competição intraespecífica pode ser a causa do não aumento na eficiência da fitorremediação pelo incremento na densidade populacional de Tanzânia, pois o excesso de plantas pode acarretar em limitação da exploração do solo, com conseqüente estabilização da interceptação/ remoção do herbicida pelo sistema radicular das plantas de Tanzânia.

O plantio de Tanzânia estimulou o crescimento das plantas de soja, semeadas em sucessão, em solo onde não houve a aplicação do picloram, o que pode ser verificado pela maior altura de plantas em relação à testemunha sem fitorremediação (Tabela 3 e Figura 2). Isso mostra mais um possível benefício da utilização dessa cultivar em programas de fitorremediação, que visem à introdução na área da cultura da soja. Quando não houve o cultivo prévio do Tanzânia, a altura das plantas de soja decresceu significativamente aos 15 e $40 \mathrm{DAE}$, quando a esta foi cultivada em solo com a presença do picloram nos dois níveis iniciais de contaminação (80 e $160 \mathrm{~g}$ $\left.\mathrm{ha}^{-1}\right)$. Aos 40 DAE a altura média das plantas de soja crescendo em solo sem herbicida foi de $28,55 \mathrm{~cm}$, enquanto que nos solos contaminados as plantas não atingiram em média $4 \mathrm{~cm}$ (Tabela 3 ). Scifres et al. (1972) registram que plantas de feijão e girassol podem exibir sintomas de intoxicação quando cultivadas em solos que contêm menos de 10 ppb de picloram.

Aos 15 DAE, a implantação da fitorremediação com plantas de Tanzânia, nas três densidades avaliadas $\left(122,244\right.$ e 366 plantas $\left.\mathrm{m}^{-2}\right)$, impediu a redução do porte das plantas de soja, mesmo no maior nível de contaminação do solo $\left(160 \mathrm{~g} \mathrm{ha}^{-1} \mathrm{de}\right.$ picloram) (Tabela 3 e Figura 2). Esse desempenho também ocorreu aos 40 DAE, com exceção da densidade populacional de 366 plantas $\mathrm{m}^{-2}$ de Tanzânia, que não impediu que ocorresse redução na altura das plantas de soja quando cultivada em solo que recebeu a aplicação de $160 \mathrm{~g} \mathrm{ha}^{-1}$ do herbicida (Tabela 3). Quando o objetivo é a fitorremediação de uma área, comumente, utiliza-se densidade maior que aquela recomendada para o cultivo comercial (LINDSAY et al., 2003). Todavia, a avaliação da altura das plantas bioindicadoras mostrou novamente a tendência de queda da eficiência da fitorremediação com o aumento da densidade das plantas remediadoras, a partir de, aproximadamente, 122 plantas $\mathrm{m}^{-2}$ de Tanzânia (Figura 2). Tal fato fica mais evidente quando o nível inicial de contaminação é maior, o que exige também um incremento na ação das plantas remediadoras. 
Tabela 3. Altura de plantas de soja semeadas após o cultivo prévio de Panicum maximum (cultivar Tanzânia), em quatro densidades populacionais, em solo contaminado com três níveis do herbicida picloram. Rio Verde, GO. 2006/2007.

\begin{tabular}{lcccc}
\hline \multirow{2}{*}{ Doses de picloram $\left(\mathrm{g} \mathrm{ha}^{-1}\right)$} & \multicolumn{4}{c}{ Plantas de Panicum maximum (cultivar Tanzânia) $\mathrm{m}^{-2}$} \\
\cline { 2 - 4 } & \multicolumn{4}{c}{ Altura de plantas de soja (cm) aos 15 DAE* } \\
\cline { 2 - 4 } & $10,75 \mathrm{a}$ & $12,48 \mathrm{a}$ & $13,55 \mathrm{a}$ & $13,00 \mathrm{a}$ \\
\hline 0 & $4,55 \mathrm{~b}$ & $12,73 \mathrm{a}$ & $12,50 \mathrm{a}$ & $12,03 \mathrm{a}$ \\
160 & $2,93 \mathrm{~b}$ & $13,48 \mathrm{a}$ & $12,05 \mathrm{a}$ & $10,60 \mathrm{a}$ \\
\hline & \multicolumn{4}{c}{ Altura de plantas de soja $(\mathrm{cm})$ aos 40 DAE } \\
\hline 0 & $28,55 \mathrm{a}$ & $46,13 \mathrm{a}$ & $41,70 \mathrm{a}$ & $41,83 \mathrm{a}$ \\
80 & $3,38 \mathrm{~b}$ & $42,23 \mathrm{a}$ & $36,30 \mathrm{a}$ & $35,05 \mathrm{a}$ \\
160 & $3,33 \mathrm{~b}$ & $45,30 \mathrm{a}$ & $40,23 \mathrm{a}$ & $21,38 \mathrm{~b}$ \\
\hline
\end{tabular}

Médias não seguidas de mesma letra na vertical diferem pelo teste de Tukey a $5 \%$ de probabilidade. $*$ DAE $=$ dias após a emergência. **a e b representam as comparações entre médias pelo de Tukey a 5\%.

15 DAE

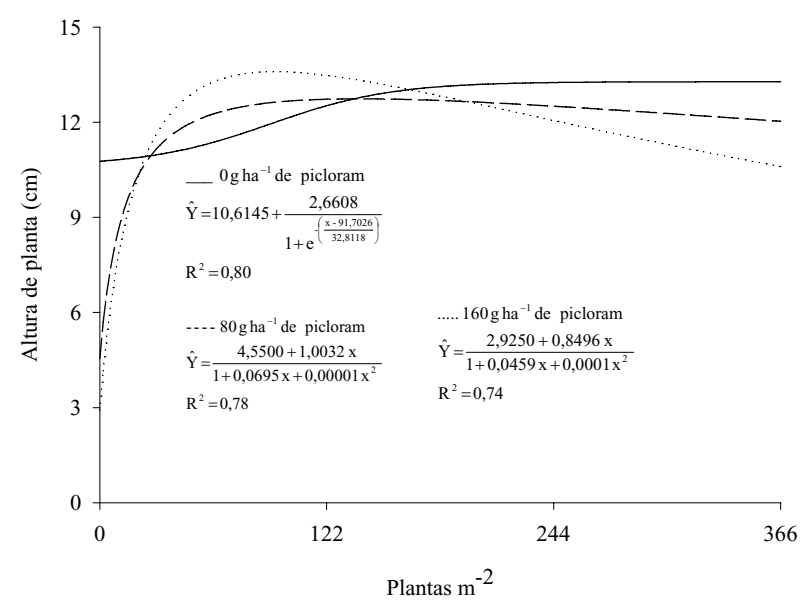

$40 \mathrm{DAE}$

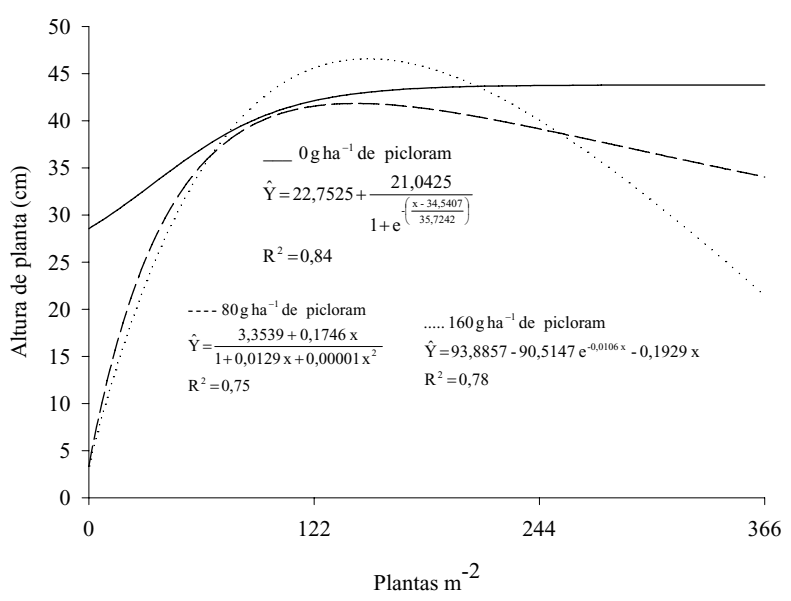

Figura 2. Altura de plantas de soja, aos 15 e 40 dias após a emergência (DAE), semeadas após o cultivo prévio de Panicum maximum (cultivar Tanzânia), em quatro densidades populacionais, em solo contaminado com três níveis do herbicida picloram. Rio Verde, GO. 2006/2007.

O acúmulo de fitomassa por plantas de soja foi favorecidopelocultivoanteriordeplantasdeTanzânia, independentemente da presença ou não do picloram no solo, reforçando a existência de outros benefícios advindos do cultivo prévio dessa forrageira, que não somente a atividade fitorremediadora (Tabela 4), o que consiste num dos aspectos, não obrigatórios, mas desejáveis, nas plantas que se destinem a programas de fitorremediação (PIRES et al., 2003). A atividade residual do picloram no solo resultou em diminuição drástica da massa verde e seca da parte aérea das plantas de soja aos $40 \mathrm{DAE}$, quando não foi realizada a fitorremediação do solo com as plantas de Tanzânia (Tabela 4 e Figura 3). Todas as densidades populacionais de Tanzânia (122, 244 e 366 plantas $\mathrm{m}^{-2}$ ) foram capazes de garantir o acúmulo da fitomassa das plantas bioindicadoras, quando essas foram cultivadas em solo contaminado com 80 ou $160 \mathrm{~g} \mathrm{ha}^{-1}$ de picloram, excetuando-se o emprego de 366 plantas $\mathrm{m}^{-2}$ de Tanzânia em solo que recebeu 
$160 \mathrm{~g} \mathrm{ha}^{-1}$ do herbicida, situação em que se verificou a menor quantidade de massa verde e seca na parte aérea das plantas de soja (Tabela 4). A partir de 122 plantas $\mathrm{m}^{-2}$ de Tanzânia, o aumento da população dessa forrageira, também demonstrou relação inversa com a eficácia da técnica descontaminadora de solos com a presença desse xenobiótico, sendo tal fato mais evidente em solo com a maior atividade residual do herbicida (Figura 3).

Tabela 4. Massa verde e massa seca de plantas de soja semeadas após o cultivo prévio de Panicum maximum (cultivar Tanzânia), em quatro densidades populacionais, em solo contaminado com três níveis do herbicida picloram. Rio Verde, GO. 2006/2007.

\begin{tabular}{|c|c|c|c|c|}
\hline \multirow{3}{*}{ Doses de picloram $\left(\mathrm{g} \mathrm{ha}^{-1}\right)$} & \multicolumn{4}{|c|}{ Plantas de Panicum maximum (cultivar Tanzânia) $\mathrm{m}^{-2}$} \\
\hline & 0 & 122 & 244 & 366 \\
\hline & \multicolumn{4}{|c|}{ Massa verde da parte aérea de plantas de soja (g) aos $40 \mathrm{DAE}^{*}$} \\
\hline 0 & $41,35 \mathrm{a}$ & $98,60 \mathrm{a}$ & $74,50 \mathrm{a}$ & $94,45 \mathrm{a}$ \\
\hline 80 & $3,98 \mathrm{~b}$ & $90,00 \mathrm{a}$ & $61,53 \mathrm{a}$ & $68,30 \mathrm{a}$ \\
\hline \multirow[t]{2}{*}{160} & $3,48 \mathrm{~b}$ & $96,00 \mathrm{a}$ & $84,53 \mathrm{a}$ & $25,05 \mathrm{~b}$ \\
\hline & \multicolumn{4}{|c|}{ Massa seca da parte aérea de plantas de soja (g) aos 40 DAE } \\
\hline 0 & $13,55 \mathrm{a}$ & $27,23 \mathrm{a}$ & 24,48 a & $27,60 \mathrm{a}$ \\
\hline 80 & $3,25 \mathrm{~b}$ & $25,75 \mathrm{a}$ & $21,33 \mathrm{a}$ & $20,90 \mathrm{a}$ \\
\hline 160 & $2,00 \mathrm{~b}$ & $27,10 \mathrm{a}$ & $24,85 \mathrm{a}$ & $11,13 \mathrm{~b}$ \\
\hline
\end{tabular}

Médias não seguidas de mesma letra na vertical diferem pelo teste de Tukey a 5\% de probabilidade. *DAE = dias após a emergência. **a e b representam as comparações entre médias pelo de Tukey a 5\%.
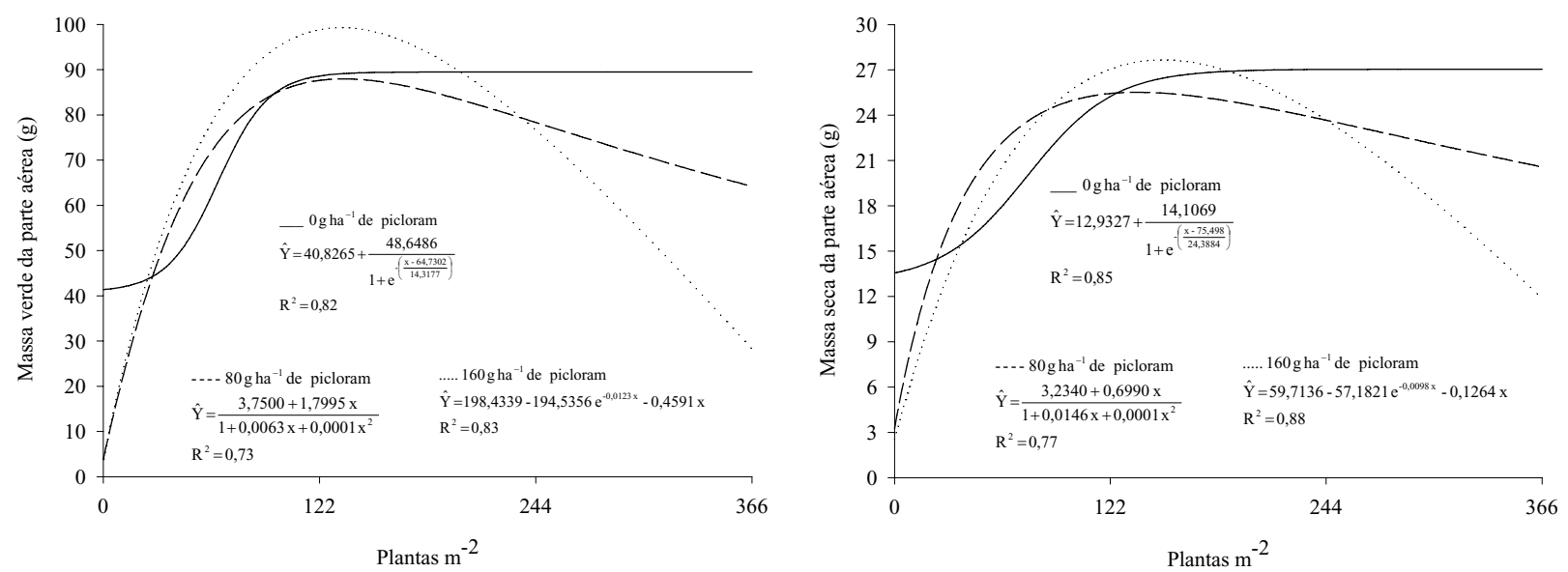

Figura 3. Massa verde e massa seca de plantas de soja, aos 40 dias após a emergência (DAE), semeadas após o cultivo prévio de Panicum maximum (cultivar Tanzânia), em quatro densidades populacionais, em solo contaminado com três níveis do herbicida picloram. Rio Verde, GO. 2006/2007. 
Santos et al. (2006a) verificaram que a densidade populacional mínima da espécie fitorremediadora Canavalia ensiformis que possibilitou o melhor desenvolvimento e a máxima produtividade do feijoeiro cultivado em solo contaminado com o herbicida trifloxysulfuron sodium, foi de 20 plantas $\mathrm{m}^{-2}$, correspondendo a 2,5 vezes àquela recomendada na adubação verde, concordando com Procópio et al. (2005 a), que avaliaram a mucuna-preta (Stizolobium aterrimum) na remediação do herbicida trifloxysulfuron sodium. Para o Tanzânia no presente trabalho, a densidade de 122 plantas $\mathrm{m}^{-2}$ equivale aproximadamente à densidade comercialmente recomendada, o que incrementa a potencialidade de utilização dessa espécie na fitorremediação de picloram por não representar aumento significativo nos custos para aplicação da técnica.

É importante ressaltar que os dados obtidos nesse trabalho são referentes apenas ao cultivar Tanzânia, pois em avaliações prévias, outros cultivares comerciais de Panicum maximum não demonstraram a mesma capacidade de remediação.

\section{Conclusões}

Panicum maximum cv. Tanzânia influencia o nível de fitotoxicidade do herbicida picloram sobre a cultura da soja semeada em sucessão e tem capacidade de remediar solos contaminados com esse herbicida.

Este processo é influenciado pela densidade populacional da espécie fitorremediadora $P$. maximum cv. Tanzânia alcançando seu máximo com 122 plantas $\mathrm{m}^{-2}$ havendo decréscimo com populações maiores.

\section{Referências}

BARRA, R.; MAFFIOLI, G.; NOTARIANNI, P.; MAZZUCHELLI, P.; VIGHI, M. Patrones de contaminación por herbicidas en aguas superficiales en una cuenca agrícola. Ecotoxicology and Environmental Restoration, Coimbra, v. 2, n. 1, p. 75-83, 1999.
BRIGHENTI, A. M.; MORALES, V. J.; OLIVEIRA JUNIOR, R. S.; GAZZIERO, D. L.; VOLL, E.; GOMES, J. A. Persistência e fitotoxicidade do herbicida atrazine aplicado na cultura do milho sobre a cultura do girassol em sucessão. Planta Daninha, Viçosa, v. 20, n. 2, p. 291297, 2002.

EMPRESA BRASILEIRA DE PESQUISA AGROPECUÁRIA - EMBRAPA. Centro Nacional de Pesquisa de Solos. Manual de métodos de análise de solo. 2. ed. Rio de Janeiro: Emprapa-CNPS, 1997.

JAKELAITIS, A.; VIVAN, R.; SANTOS, J. B.; SILVA, A. A.; SILVA, A. F. Atividade residual no solo da mistura comercial dos herbicidas fluazifop-p-butil e fomesafen utilizados no cultivo convencional e direto do feijoeiro. Planta Daninha, Viçosa, v. 24, n. 3, p. 533540, 2006.

KOLPIN, D. W.; THURMAN, E. M.; GOOLSBY, D. A. Occurrence of selected pesticides and their metabolites in near-surface aquifers of the midwestern United States. Environmental Science \& Technology, Missouri, v. 30, n. 1, p. 335-340, 1996.

KRUTZ, L. J.; SENSEMAN, S. A.; ZABLOTOWICZ, R. M.; MATOCHA, A. Reducing herbicide runoff from agricultural fields with vegetative filter strips: a review. Weed Science, Washington, v. 53, n. 3, p. 353-367, 2005.

LERCH, R. N.; BLANCHARD, P. E.; THURMAN; E. M. Contribution of hydroxylated atrazine degradation products to the total atrazine load in Midwestern streams. Environmental Science \& Technology, Missouri, v. 32, n. 1, p. 40-48, 1998.

LERCH, R. N.; DONALD, W. W.; LI, Y. X.; ALBERTS, E. E. Hydroxylated atrazine degradation products in small Missouri streams. Environmental Science \& Technology, Missouri, v. 29, n. 11, p. 2759-2768, 1995.

LINDSAY, E.B.; BURKHEAD, J.L.; HALE, K.L.; TERRY, N.; PILON, M. \& PILON-SMITS, E.A.H. Analysis of transgenic indian mustard plants for phytoremediation of metal-contaminated mine tailings. Journal of Environmental Quality, Medison, v. 32, n. 2, p. 432-440, 2003.

PALMA, G.; SANCHES, A.; OLAVE, Y.; ENCINA, F.; PALMA, R.; BARRA, R. Pesticides levels in surfaces waters in an agricultural-forestry basin in Southern Chile. Chemosphere, Amsterdan, v. 57, n. 8, p. 763-770, 2004.

PILON-SMITS, E. Phytoremediation. Annual Reviews of Plant Biology, Palo Alto, v. 56, n. 1, p. 15-39, 2005. 
PIRES, F. R.; SOUZA, C. M.; SILVA, A. A.; PROCÓPIO, S. O.; FERREIRA, L. R. Fitorremediação de solos contaminados por herbicidas. Planta Daninha, Viçosa, v. 21, n. 2, p. 335-341, 2003.

PIRES, F. R.; PROCÓPIO, S. O.; SOUZA, C. M.; SANTOS, J. B.; SILVA, G. P. Adubos verdes na fitorremediação de solos contaminados com o herbicida tebuthiuron. Caatinga, Mossoró, v. 19, n. 1, p. 92-97, 2006.

PIRES, F. R.; SOUZA, C. M.; CECON, P. R.; SANTOS, J. B.; TÓTOLA, M. R.; PROCÓPIO, S. O.; SILVA, A. A.; SILVA, C. S. W. Inferências sobre atividade rizosférica de espécies com potencial para fitorremediação do herbicida tebuthiuron. Revista Brasileira de Ciência do Solo, Viçosa, v. 29, n. 4, p. 627-634, 2005a.

PIRES, F. R.; SOUZA, C. M.; SILVA, A. A.; CECON, P. R.; PROCOPIO, S. O.; SANTOS, J. B.; FERREIRA, L. R. Fitorremediação de solos contaminados com tebuthiuron utilizando-se espécies cultivadas para adubação verde. Planta Daninha, Viçosa, v. 23, n. 4, p. 711-717, 2005 b.

PROCÓPIO, S. O.; SANTOS, J. B.; PIRES, F. R.; SILVA, A.A.; SANTOS, E.A.; FERREIRA, L. R. Fitorremediação de solo contaminado com trifloxysulfuron sodium por mucuna-preta (Stizolobium aterrimum). Planta Daninha, Viçosa, v. 23, n. 4, p. 719-724, 2005 a.

PROCÓPIO, S. O.; SANTOS, J. B.; SILVA, A. A.; PIRES, F. R.; RIBEIRO JÚNIOR, J. I.; SANTOS, E. A. Potencial de espécies vegetais para a remediação do herbicida trifloxysulfuron-sodium. Planta Daninha, Viçosa, v. 23, n. 1, p. 9-16, 2005 b.

PROCÓPIO, S. O.; SANTOS, J. B.; PIRES, F. R.; SILVA, A. A.; SANTOS, E. A.; CARGNELUTTI FILHO, A. Development of bean plants in soil contaminated with trifloxysulfuron-sodium after Stizolobium aterrimum and Canavalia ensiformis cultivation. Planta Daninha, Viçosa, v. 25, n. 1, p. 87-96, 2007.

ROUSSEAUX, S.; HARTMANN, A.; ROUARD, N.; SOULAS, G. A simplified procedure for terminal restriction fragment length polymorphism analysis of the soil bacterial community to study the effects of pesticides on the soil microflore using 4,6-dinitroorthocresol as test case. Biology and Fertility of Soils, Heidelberg, v. 37, n. 4, p. 250-254, 2003.
SANTOS, J. B.; PROCÓPIO, S. O.; PIRES, F. R.; SILVA, A. A.; SANTOS, E. A Fitorremediação de solo contaminado com trifloxysulfuron-sodium por diferentes densidades populacionais de feijão-de-porco (Canavalia ensiformis (1). dc.). Ciência e Agrotecnologia, Lavras, v. 30, n. 3, p. 444-449, 2006 a.

SANTOS, M. V.; FREITAS, F. C. L.; FERREIRA, F. A.; VIANA, R. G.; TUFFI SANTOS, L. D.; FONSECA, D. M. Eficácia e persistência no solo de herbicidas utilizados em pastagem. Planta Daninha, Viçosa, v. 24, n. 2, p. 391398, 2006b.

SANTOS, J. B.; PROCÓPIO, S. O.; SILVA, A. A.; PIRES, F. R.; RIBEIRO JÚNIOR, J. I.; SANTOS, E. A.; FERREIRA, L. R.. Fitorremediação do herbicida trifloxysulfuron sodium. Planta Daninha, Viçosa, v. 22, n. 2, p. 223-330, 2004.

SCHNOOR, J. L.; DEE, P. E. Technology evaluation report: phytoremediation. Pittsburgh: Ground-Water Remediation Technologies Analysis Center, 1997. (E Series: GWRTAC TE-98-01).

SCIFRES, C. J.; BOVEY, R. W.; MERKLE, M. G. Variation in bioassay attributes as quantitative indices of picloram in soils. Weed Research, Oxford, v. 12, n. 1, p. 58-64, 1972.

THURMAN, E. M.; GOOLSBY, D. A.; MEYER, M. T.; MILLS, M. S.; POMES, M. L.; KOLPIN, D. W. A reconnaissance study of herbicides and their metabolites in surface-water of the Midwestern United States using immunoassay and gas chromatography/mass spectrometry. Environmental Science \& Technology, Missouri, v. 26, n. 12, p. 2440-2447, 1992.

VILLA, S. C. C.; MARCHEZAN, E.; AVILA, L. A.; MASSONI, P. F. S.; TELO, G. M.; MACHADO, S. L. O.; CAMARGO, E. R. Arroz tolerante a imidazolinonas: controle do arroz-vermelho, fluxo gênico e efeito residual do herbicida em culturas sucessoras não-tolerantes. Planta Daninha, Viçosa, v. 24, n. 4, p. 761-768, 2006.

WAX, L. M.; KNUTH, L. A.; SLIFE, F. W. Response of soybeans to 2,4-D, dicamba and picloram. Weed Science, Gainsville, v. 17, n. 3, p. 388-393, 1969. 